\title{
Maternal undernutrition increases pancreatic IGF-2 and partially suppresses the physiological wave of $\beta$-cell apoptosis during the neonatal period
}

\author{
Laura de Miguel-Santos ${ }^{1,2 *}$, Elisa Fernández-Millán ${ }^{2 \star}$, María Ángeles Martín ${ }^{2,3}$, \\ Fernando Escrivá ${ }^{1,2}$ and Carmen Álvarez ${ }^{1,2}$ \\ ${ }^{1}$ Departamento de Bioquímica y Biología Molecular II, Facultad de Farmacia, Universidad Complutense de Madrid, UCM, 28040 Madrid, Spain \\ ${ }^{2}$ CIBER de Diabetes y Enfermedades Metabólicas Asociadas (CIBERDEM), ISCIII, Madrid, Spain \\ ${ }^{3}$ Departamento de Metabolismo y Nutrición, Instituto del Frío, CSIC, Madrid, Spain \\ (Correspondence should be addressed to C Álvarez at Departamento de Bioquímica y Biología Molecular II, Facultad de Farmacia, Universidad Complutense de Madrid, UCM; \\ Email: calvarez@farm.ucm.es) \\ *(L de Miguel-Santos and E Fernández-Millán contributed equally to this work)
}

\begin{abstract}
Replication, neogenesis, and apoptosis play a main role in neonatal endocrine pancreas remodeling. IGFs are major contributors to $\beta$-cell growth and function and are highly sensitive to nutritional status. We previously showed that maternal malnutrition caused an increase in $\beta$-cell mass in fetuses related to the stimulation of $\beta$-cell proliferation due to increased pancreatic IGF-1. At 4 days of life, the $\beta$-cell mass was decreased in undernourished neonates and persisted until adult age. To clarify whether undernutrition disrupts islet remodeling, we quantified $\beta$-cell mass, neogenesis, replication, and apoptosis on days 4,14 , and 23 . To determine the impact of food restriction on IGF ontogeny and the consequences for $\beta$-cell growth, we measured IGF-1/-2 protein content in pancreas and liver and pancreatic IGF-1 receptor (IGF-1R)-signaling pathway at the same days. Our results indicate that undernutrition alters the timing and intensity of neonatal $\beta$-cell ontogeny. However, although malnutrition causes $\beta$-cell deficiency in neonates, an active process of $\beta$-cell neogenesis and a lower incidence of $\beta$-cell apoptosis maintain the regenerative capacity of the endocrine pancreas. Interestingly, our data provide evidence that local production of IGFs seems to be instrumental in these processes. In particular, increased pancreatic IGF-2 in undernourished rats may contribute to the partial suppression of the developmental wave of $\beta$-cell apoptosis probably through the inhibition of glycogen synthase kinase-3. In addition, decreased pancreatic levels of IGFBP-1/-2/-3 in undernourished neonates could enhance IGF availability for interacting with IGF-1R/IR.
\end{abstract}

Journal of Molecular Endocrinology (2010) 44, 25-36

\section{Introduction}

It is generally accepted that the developing endocrine pancreas undergoes substantial remodeling during the neonatal period and that replication, neogenesis, and apoptosis play main roles in this process. In rodents, many of the $\beta$-cells proceeding from fetal origin are destroyed during neonatal life in a developmental wave of apoptosis to be later replaced by neogenesis or replication (Bonner-Weir 2000). Consequently, the new islets have insulin release characteristics suited to postnatal life and diet. Along these lines, the balance between $\beta$-cell growth and death determines an adequate development of $\beta$-cell mass, and any deregulation of these processes due to abnormal availability of hormones and growth factors could be of great importance for the functionality of the pancreas.
There is considerable evidence for the role of insulin and insulin-like growth factors (IGF-1 and -2) in the development, maturation, and function of $\beta$-cells. It is known that IGFs and their binding proteins (IGFBPs) are expressed by islet cells throughout life (Hill et al. 1999). In rats, IGF-2 levels are relatively high in fetal and early neonatal period and then they decline sharply toward adulthood, while IGF-1 levels increase progressively with age (Hogg et al. 1994, Petrik et al. 1998). Both IGFs are considered as survival factors by inhibiting $\beta$-cell apoptosis. It has been shown that the transient wave of apoptosis that occurs in developing rat islets between the first and second week of postnatal life (Scaglia et al. 1997, Petrik et al. 1998) is temporally associated with a lack of expression of IGF-2 within pancreatic islets (Petrik et al. 1998); in fact, persistent circulating IGF-2 abolishes neonatal islet apoptosis (Hill et al. 2000). Similarly, IGF-1 has also been 
implicated in $\beta$-cell protection from cytokine-induced cell death (Casellas et al. 2006). IGFs mediate their biological actions via the IGF-1 receptor (IGF-1R), which involves the interaction of the IGF-1R with the insulin receptor substrates (IRS-1/-2) and the activation of phosphatidylinositol 3-kinase and Akt (Liu et al. 2002). Once activated, Akt integrates multiple survival signals inducing the phosphorylation-inactivation of pro-apoptotic proteins such as Bcl-associated death promoter (Bad) or glycogen synthase kinase-3 (GSK-3; Liu et al. 2002).

A worldwide series of epidemiological data support the concept that dietary influences during early stages of development present a risk factor for the onset of both perinatal and later life diseases. The extensive changes in islet cells throughout the neonatal life could explain why pancreatic morphology and function are so sensitive to nutritional insult at this time. Indeed, several studies in experimental models with rats submitted to different patterns of malnutrition have reported that maternal food restriction significantly affects the $\beta$-cell mass in the fetuses (Alvarez et al. 1997, Bertin et al. 2002) and in the offspring neonates at day 1 (Garofano et al. 1999) and day 4 of postnatal life (Martín et al. 1997). This effect persists until adulthood (Martín et al. 1997) and can provoke long-lasting consequences related to the plasticity of the endocrine pancreas under situations of increased insulin demand such as aging (Garofano et al. 1999) and pregnancy (Blondeau et al. 1999). Accordingly, nutritional insufficiency can alter the timing and amplitude of the ontological events, which trigger the remodeling of endocrine pancreas (Petrik et al. 1999).

We previously reported that protein-caloric food restriction ( $65 \%$ of ad libitum intake) applied during the last third of gestation caused an increase of $\beta$-cell mass in fetuses at term (Alvarez et al. 1997), associated to the stimulation of $\beta$-cell proliferation due to locally increased pancreatic IGF-1 and islet IRS-2 production (Martín et al. 2005, Fernández et al. 2007). Nevertheless, food restriction continued after birth induced a decrease in $\beta$-cell mass at 4 days of life and this effect persisted until adult age (Martín et al. 1997). We consider that this chronic severe deficiency represents better condition of undernourished humans in developing countries, and it is a very useful tool to investigate the impact of a permanent undernutrition state on pancreas plasticity. Therefore, in order to clarify whether the programmed turnover of pancreatic $\beta$-cells occurs following the same pattern of growth and by the same mechanisms in control and undernourished neonates, in this study, we quantified the $\beta$-cell mass, $\beta$-cell neogenesis, replication, and apoptosis at 4,14 , and 23 days of age. Since the IGF system is highly sensitive to nutritional status (Thissen et al. 1994), the second aim in the present study was to determine the impact of food restriction on the IGF protein expression profile and signaling pathways through the suckling period and the consequences for the growth of $\beta$-cells.

\section{Materials and methods}

\section{Animals and diets}

Neonatal Wistar rats bred in our laboratory under a controlled temperature and artificial dark-light cycle (from 0700 to 1900) were used throughout the study. Virgin females were caged with males, and mating was confirmed by the presence of spermatozoa in a vaginal smear. Each dam was housed individually from the 14th day, and maternal food restriction was established. All animals were fed a standard laboratory diet (Panlab No. A04: $19.3 \%$ protein, $2.9 \%$ lipids, $57 \%$ carbohydrates (starch and sucrose), $4.5 \%$ cellulose, a vitamin and mineral mix, and $12 \%$ water; Barcelona, Spain) and were divided into two groups: control pregnant dams were fed ad libitum; and the undernourished group received $35 \%$ of the food intake of a control pregnant along the third week of gestation and suckling period. The animals had free access to water. At the time of birth, litters were uniformed to eight pups per nursing dam to minimize the effects of litter size on postnatal growth, and pups were killed on days 4, 14, and 23 of postnatal life.

Before killing by decapitation, the neonates were weighed, blood samples were collected, and serum and plasma were separated and stored frozen at $-20{ }^{\circ} \mathrm{C}$ until analyzed. Pancreases and livers were removed and weighed. For western blot analyses, pancreases and livers were immersed in liquid nitrogen and stored at $-70{ }^{\circ} \mathrm{C}$ until analyses. For immunohistochemistry and morphometric studies, pancreases were fixed in aqueous Bouin's solution during $24 \mathrm{~h}$ and embedded in paraffin.

All studies were conducted according to the principles and procedures outlined in the National Institute of Health Guidelines for Care and Use of Experimental Animals and approved by the Animal Ethics Committee of the Complutense University of Madrid (Spain).

\section{Analytical determinations}

Aliquots of $10 \mu \mathrm{l}$ obtained from $30 \mu \mathrm{Ba}(\mathrm{OH})_{2}-\mathrm{ZnSO}_{4}$ deproteinized blood were used to determine glucose by a glucose oxidase method (Boehringer-Mannheim). Serum insulin was determined with a rat insulin RIA (Linco Research Inc., St Louis, MO, USA) with rat insulin used for standard curve. Sensitivity of $0 \cdot 1 \mathrm{ng} / \mathrm{ml}$ was achieved with overnight equilibration using a $100 \mu \mathrm{l}$ serum sample. Serum glucagon was determined with a glucagon RIA purchased from Linco; sensitivity of 
$20 \mathrm{pg} / \mathrm{ml}$ was achieved using $100 \mu \mathrm{l}$ serum sample in a 2-day disequilibrium assay. Serum growth hormone $(\mathrm{GH})$ was determined with a rat $\mathrm{GH}{ }^{125} \mathrm{I}$ assay system (Amersham, GE Healthcare). The sensitivity of the assay was $1.6 \mathrm{ng} / \mathrm{ml}$. Serum IGF-1 was measured by a mouse/rat IGF-1 RIA (Diagnostic System Laboratories, Websters, TX, USA). The method incorporates a sample pretreatment to avoid interference from IGFBPs. Serum IGF-2 was measured by radioreceptor assay as previously described (Rivero et al. 1995).

\section{Immunohistochemistry and morphometry}

Immunohistochemistry was performed as previously described (Fernández et al. 2006). Pancreas sections $(5 \mu \mathrm{m})$ at fixed intervals throughout the paraffin block were immunostained for insulin using guinea pig anti-porcine insulin (ICN, Biolink, Barcelona, Spain) and a peroxidase-conjugated rabbit anti-guinea pig IgG (Dako Diagnostics, Barcelona, Spain). Immunoreactivity was localized using a peroxidase substrate kit (DAB; Vector, Grupo Taper, Madrid, Spain). Quantitative evaluation was performed using computer-assisted image analysis performed by means of an Olympus BX40 microscope connected via a video camera to a PC computer and using the Histolab 5.2 software (Microvision Instruments, Evry, France). The area of insulin-positive cells and that of total pancreatic sections was evaluated in each stained section. $\beta$-Cell relative volume was determined by calculating the ratio between the area occupied by insulin immunoreactive cells and that occupied by total pancreatic cells. Total $\beta$-cell mass per pancreas was derived by multiplying the total pancreatic weight by the $\beta$-cell relative volume. The total islet number per section $\left(\mathrm{cm}^{2}\right.$ of pancreatic tissue) was counted, and islets were arbitrarily classified as very small $(\leq 30 \mu \mathrm{m}$ in diameter), small $(31-50 \mu \mathrm{m}$ in diameter), medium (51-150 $\mu \mathrm{m}$ in diameter), or large ( $\geq 151 \mu \mathrm{m}$ in diameter) to evaluate the distribution of islet sizes. To obtain an estimation of $\beta$-cell neogenesis activation, we quantified on every section immunostained for insulin the number of single $\beta$-cells and $\beta$-cell clusters (2-4) incorporated into the ductal epithelium. The values obtained were related to the total area of the pancreatic section and calculated per micrometer squared of the pancreatic area. Results represent the average of four to five tissue sections per animal from four to six animals from each experimental group and age.

\section{$\beta$-Cell replication}

Other pancreas sections were used to measure $\beta$-cell replication rate as previously described (Fernández et al. 2006). In each group, neonates were injected with 5'-bromo-2'deoxyuridine (BrdU), $50 \mathrm{mg} / \mathrm{kg}$ body weight i.p. (Sigma-Aldrich) $1 \mathrm{~h}$ before killing. Sections were double stained. First, for detection of BrdUpositive cells, it was used with a cell proliferation kit (Cell Proliferation kit; Amersham, GE Healthcare) with a mouse monoclonal anti-BrdU antibody and a peroxidase anti-mouse IgG. Immunoreactivity was localized using the peroxidase substrate kit DAB (Vector). Then insulin staining was performed using a guinea pig polyclonal anti-insulin antibody (ICN). This antibody was recognized with a rabbit anti-guinea pig alkaline phosphatase-conjugated antibody (ICN), which was revealed with alkaline phosphatase substrate kit I (Vector). The $\beta$-cell replication rate was expressed as the percentage of BrdU-positive $\beta$-cells. At least, 1500 $\beta$-cells were counted per pancreas.

\section{$\beta$-Cell apoptosis}

In situ detection and quantification of $\beta$-cell apoptosis were done within histological sections of pancreas by using a TUNEL cell death detection kit (ApopTag Peroxidase In Situ Apoptosis detection kit, Chemicon International, Millipore, Madrid, Spain) according to the manufacturer's protocol and coupled to insulin staining in similar conditions to those described for BrdU/insulin labeling. The tissue was counterstained with Harri's hematoxylin for $30 \mathrm{~s}$. The $\beta$-cell apoptosis rate was expressed as the percentage of apoptotic $\beta$-cells. At least $1500 \quad \beta$-cells were counted per pancreas.

\section{Immunoprecipitation}

Tissue extracts containing $250 \mu \mathrm{g}$ protein were immunoprecipitated overnight at $4{ }^{\circ} \mathrm{C}$ with gentle rotation in the presence of $2-4 \mu \mathrm{g}$ anti-phosphotyrosine mouse monoclonal antibody (Upstate Biotechnology, Millipore, Madrid, Spain), followed by the addition of anti-mouse IgG agarose (Sigma-Aldrich). After mixing for $2 \mathrm{~h}$, the pellets were collected by centrifugation, and the supernatants were discarded. Then, the pellets were washed and saved for western blot analyses.

\section{Western blot analyses}

Frozen pancreases and livers were homogenized in ice-cold lysis buffer $(10 \mu \mathrm{M}$ leupeptin, $2 \mathrm{mM}$ $O$-vanadate, $2 \mathrm{mM}$ benzamidine, $10 \mu \mathrm{g} / \mathrm{ml}$ aprotinin, and $2 \mathrm{mM}$ phenylmethylsulfonyl fluoride in $12.5 \mathrm{mM}$ EGTA, $1.25 \mathrm{mM}$ EDTA, and $0 \cdot 25 \%$ Triton $\times$, pH: $7 \cdot 6$ ) using the IKA T10 basic Ultra-Turrax. Then, tissue extracts were cleared by microcentrifugation at $15700 \mathrm{~g}$ at $4{ }^{\circ} \mathrm{C}$ for $20 \mathrm{~min}$, and the supernatant was used for the determination of total protein content. 
The concentration of protein was determined by the Bradford method (Bradford 1976) using a protein assay (Bio-Rad Laboratories, Inc.), with $\gamma$-globulin as standard.

Equals amount of protein were separated by SDSPAGE, transferred to Immobilon membranes, and incubated overnight with the corresponding primary antibodies (anti-IGF-I, clone Sm1.2, anti-IGF-II, clone S1F2, and anti-IR $\beta$-subunit purchased from Upstate Biotechnology, Millipore; anti-IGF-1R $\beta$, anti-GSK- $3 \alpha / \beta$,

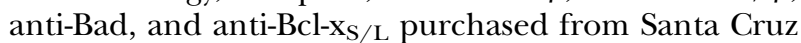
Biotechnology, Inc. (Santa Cruz, CA, USA); antiphospho-Akt (Ser473), anti-Akt, anti-phospho-GSK$3 \alpha / \beta$ (Ser21/9), and anti-phospho-Bad (Ser136) purchased from Cell Signaling Technology, Inc. (Danvers, MA, USA)). Immunoreactive bands were visualized using the ECL western blot protocol (Amersham). Normalization of western blot was ensured by $\beta$-actin (Sigma-Aldrich), and the intensity of bands was quantified by laser-scanning densitometry (Molecular Dynamics, Sunnyvale, CA, USA).

\section{Statistical analyses}

Values are given as means \pm S.E.M. for the number of rats studied. For all data comparisons, the ANOVA, followed by the protected least significant difference test, was used. Statistical analyses were performed using SPSS version 15.0 software (SPSS Inc., Chicago, IL, USA).

\section{Results}

\section{Biological characteristics of neonates}

The biological characteristics of neonates are shown in Table 1. Postnatal development is associated with a high growth rate. Here, we show that the body, pancreas, and liver weight of neonatal rats increased linearly, and this increase was significantly higher at each age studied as compared with the previous time point. In undernourished pups, the weight values were significantly lower at each time point as compared with control neonates. However, because body weights are different between control and undernourished rats when pancreas and liver weights were normalized to the body weight, no dissimilarities were found in these parameters (data not shown).

Circulatory glucose levels were similar between control and undernourished offspring through the suckling period. On the other hand, serum insulin levels were similar in both groups on day 4, but foodrestricted neonates developed hypoinsulinemia from 14 days of age onwards. Although undernourished pups showed lower glucagonemia than controls on days 4 and 14 , serum glucagon concentration was normalized on day 23.

Serum GH levels decreased progressively from day 4 to day 23 of age, and no differences were found between control and undernourished values at any time point considered. On the contrary, serum IGF-1 levels increased along the period of time considered in both populations. However, from 14 days of age until the end of suckling period, serum IGF-1 levels were significantly higher in undernourished neonates than in controls. Regarding circulatory IGF-2 levels, we could not find any difference between the ages considered or the type of diet.

\section{Postnatal evolution of $\beta$-cell mass, $\beta$-cell relative volume, and islet size}

$\beta$-Cell mass increased in control neonates from day 4 to day 14. However, it remained stable from 14 to 23 days of age. With regard to $\beta$-cell growth in the undernourished population, we did not observe any difference between 4 and 14 days of age, but there was a significant increase from postnatal day 14 to 23 . Nevertheless, the $\beta$-cell mass was markedly lower at each

Table 1 Biological characteristics of neonates at 4, 14, and 23 days of age from control and undernourished pregnant rats

\begin{tabular}{|c|c|c|c|c|c|c|}
\hline & \multicolumn{2}{|c|}{4 days of age } & \multicolumn{2}{|c|}{14 days of age } & \multicolumn{2}{|c|}{23 days of age } \\
\hline & $\mathrm{C}$ & U & $\mathrm{C}$ & $U$ & C & $U$ \\
\hline Pancreas weight (mg) & $23.8 \pm 0.5$ & $19 \cdot 0 \pm 1 \cdot 0$ & $60 \cdot 21 \pm 4 \cdot 25^{\dagger}$ & $29 \cdot 7 \pm 1 \cdot 6^{*, \dagger}$ & $220 \cdot 0 \pm 7 \cdot 0^{\dagger, \ddagger}$ & $51 \cdot 0 \pm 2 \cdot 10^{*, t, \pm}$ \\
\hline Liver weight (mg) & $277 \cdot 0 \pm 4 \cdot 0$ & $189 \cdot 0 \pm 2 \cdot 0^{*}$ & $783 \cdot 3 \pm 22 \cdot 0^{\dagger}$ & $378 \cdot 1 \pm 12 \cdot 2^{*, \dagger}$ & $2160 \pm 22 \cdot 0^{\dagger, \ddagger}$ & $468 \pm 17 \cdot 1^{\star, \dagger, \ddagger}$ \\
\hline Glycemia (mg/dl) & $101 \cdot 7 \pm 1 \cdot 5$ & $94 \cdot 4 \pm 2 \cdot 3$ & $104 \cdot 9 \pm 2 \cdot 6$ & $95 \cdot 7 \pm 3 \cdot 5$ & $110.9 \pm 3.9$ & $84 \cdot 8 \pm 3 \cdot 6$ \\
\hline Serum GH (ng/ml) & $30 \pm 5.5$ & $29 \pm 4 \cdot 2$ & $15 \cdot 2 \pm 4 \cdot 4$ & $14 \cdot 6 \pm 1 \cdot 9$ & $7 \cdot 84 \pm 0.4^{\dagger}$ & $11 \pm 2 \cdot 2^{\dagger}$ \\
\hline Serum IGF-1 (ng/ml) & $71 \cdot 2 \pm 6 \cdot 8$ & $72 \cdot 9 \pm 14 \cdot 2$ & $83 \pm 3 \cdot 3^{\dagger}$ & $261 \cdot 6 \pm 11 \cdot 5^{\star, \dagger}$ & $264 \pm 10 \cdot 6^{\dagger, \ddagger}$ & $363 \cdot 6 \pm 20 \cdot 1^{*, t, \mp}$ \\
\hline Serum IGF-2 (ng/ml) & $26 \cdot 2 \pm 1 \cdot 2$ & $28 \cdot 3 \pm 0.81$ & $27 \cdot 47 \pm 1 \cdot 1$ & $27 \cdot 1 \pm 1 \cdot 02$ & $22 \cdot 3 \pm 2 \cdot 7$ & $27 \cdot 0 \pm 0.96$ \\
\hline
\end{tabular}

Data are means \pm S.E.M. of $10-15$ animals per group and age. ${ }^{*} P<0.05$ relative to control rats at the same age; ${ }^{\dagger} P<0.05$ relative to 4 days of age within the same condition; ${ }^{\ddagger} P<0.05$ relative to 14 days of age within the same condition. 

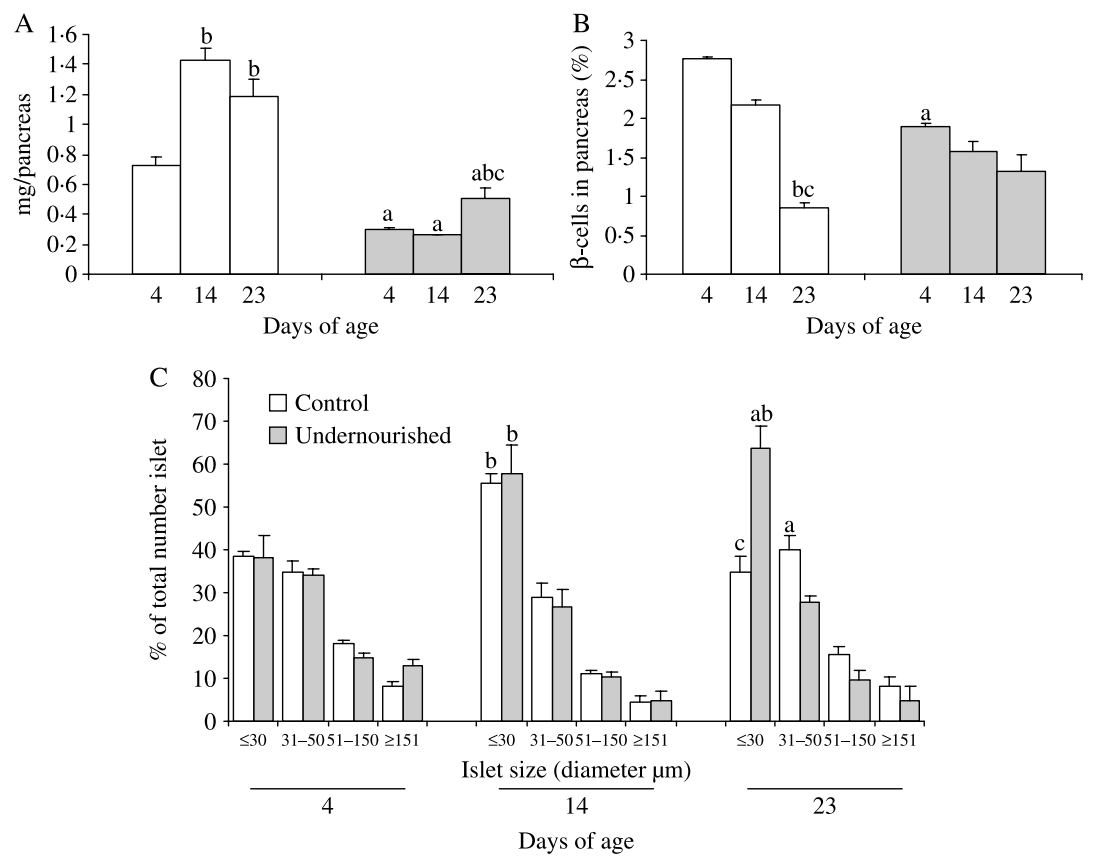

Figure $1 \beta$-Cell mass $(A)$ and $\beta$-cell relative volume $(B)$ in control and undernourished neonatal rats. Values are mean \pm S.E.M. for four to six observations in each experimental group and age. ${ }^{a} P<0.05$ relative to control rats at the same age; ${ }^{b} P<0.05$ relative to 4 days of age within the same condition; ${ }^{\mathrm{c}} P<0.05$ relative to 14 days of age within the same condition. (C) Relative distribution of arbitrarily defined very small $(\leq 30 \mu \mathrm{m})$, small $(31-50 \mu \mathrm{m})$, medium $(51-150 \mu \mathrm{m})$, or large $(\geq 151 \mu \mathrm{m})$ pancreatic islets in control and undernourished neonates at 4,14 , and 23 days of life. The comparative distribution of islet size from control and undernourished neonates at different ages is expressed in each group as a percentage of total islet number. Values are mean \pm S.E.M. for four to six observations in each experimental group and age. ${ }^{a} P<0.05$ relative to control neonates for the same age and islet size category, ${ }^{b} P<0.05$ relative to 4 days of age within the same condition and islet size category, ${ }^{\mathrm{c}} P<0.05$ relative to 14 days of age within the same condition and islet size category.

time point considered in undernourished rats as compared with the control group (Fig. 1A). On the other hand, since both populations depict different pancreas weights, we have expressed the $\beta$-cell mass data as $\beta$-cell relative volume (Fig. 1B). In control pups, the relative $\beta$-cell volume decreased progressively with time becoming three times lower on day 23 as compared with day 4 . The relative volume of $\beta$-cells remained stable over the neonatal period studied in food-restricted animals, although, at 4 days of age, this parameter was decreased by $30 \%$ as compared with the corresponding control neonates at the same time point. During all the neonatal period, most of the islets from control as well as from undernourished rats were included in the small size range $(\leq 30-50 \mu \mathrm{m}$ in diameter); however, the relative size distribution of arbitrarily defined very small, small, medium, or large islets significantly differed between control and undernourished neonates at 23 days of life, with the foodrestricted animals showing a greater percentage of very small islets as compared with control rats (Fig. 1C).

Representative images are shown in Fig. 2(A and B).

\section{$\beta$-Cell neogenesis, replication, and apoptosis}

$\beta$-Cell neoformation is shown in Fig. 3(A). In control neonates, the $\beta$-cell neogenesis decreased progressively throughout the neonatal period, while, in undernourished animals, the neoformation of $\beta$-cells remained constant between 4 and 14 days of age and then declined on day 23. The $\beta$-cell neogenesis rate was significantly higher in undernourished rats at 14 and 23 days of age as compared with age-matched control animals.

As shown in Fig. 3(B), $\beta$-cell replication peaked on day 14 in control animals, but decreased on day 23 to values lower than those observed at 4 days of life. In undernourished rats, $\beta$-cell replication remained stable from 4 to 14 days of age and then decreased significantly on day 23. The frequency of $\beta$-cell replication in undernourished neonates was significantly lower than in controls at 14 days of age.

The occurrence of apoptotic $\beta$-cell death in control neonates was $<1 \%$ on postnatal day 4 , but, at 14 days of age, the $\beta$-cells experienced a peak of apoptosis 

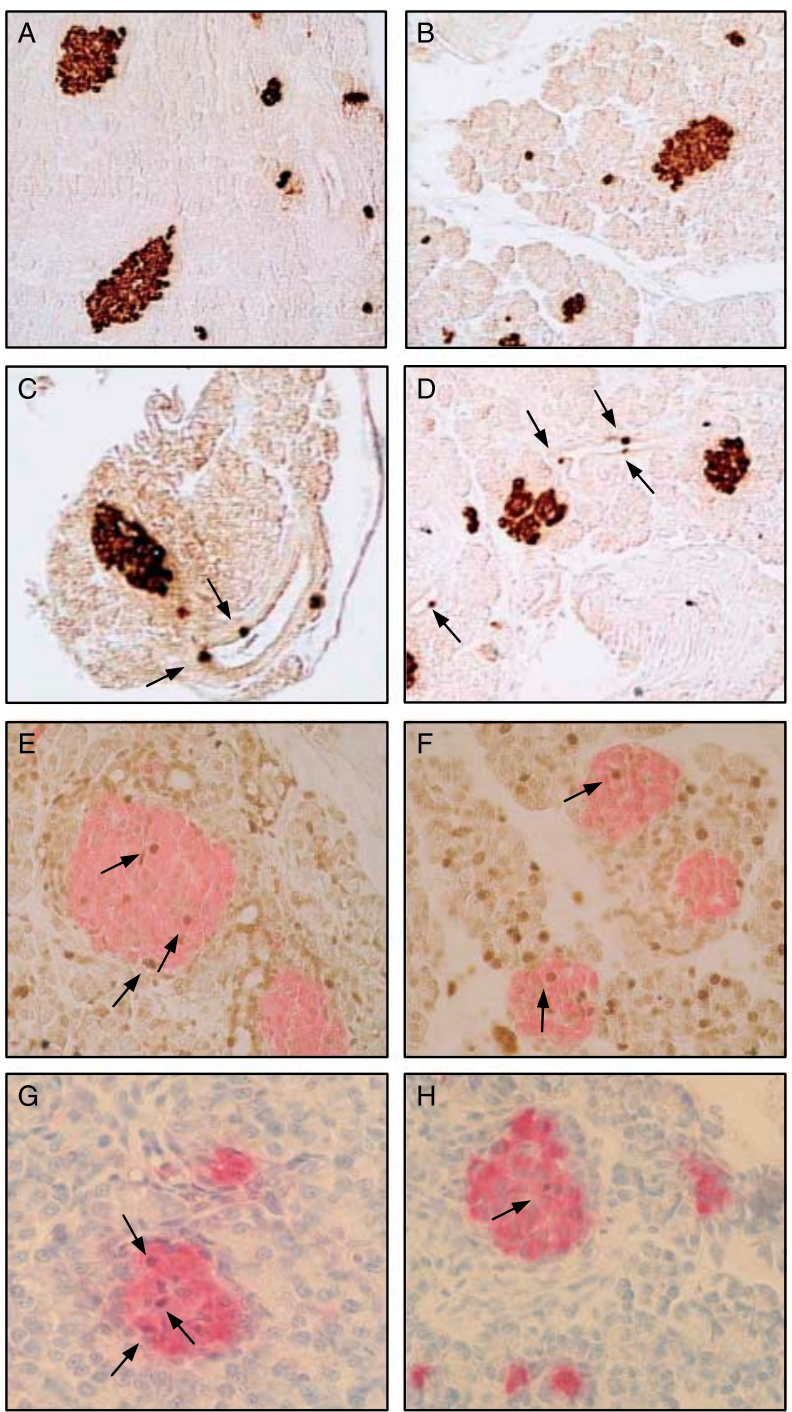

Figure 2 Immunostaining for pancreatic insulin in control and undernourished neonates (A and $B$ ) was used to measure $\beta$-cell mass. $\beta$-Cell neoformation from ducts in control and undernourished neonates $(C$ and $D)$ was illustrated by single $\beta$-cells and $\beta$-cell clusters $(2-4)$, incorporated into the ductal epithelium. Double immunostaining for BrdU and insulin was used to measure $\beta$-cell replication in control and undernourished neonatal pancreases ( $E$ and $F$ ). Double immunostaining for apoptosis and insulin was used to measure $\beta$-cell apoptosis in control and undernourished neonatal pancreases $(G$ and $H)$. All images correspond to postnatal day 14. Magnification: $20 \times$ for $A-D$ and $40 \times$ for $\mathrm{E}-\mathrm{H}$.

doubling the 4-day-old values (Fig. 3C). The incidence of $\beta$-cell apoptosis in undernourished pups also showed a rise on day 14 , but at all the neonatal ages studied the percentage of apoptotic $\beta$-cells was significantly lower in undernourished rats as compared with the agematched controls.

Representative images are shown in Fig. 2(C-H).

\section{Pancreatic and hepatic IGF-1/-2 protein levels}

Because the IGF system is highly responsive to nutritional status and there is enough evidence of the relationship between IGFs and $\beta$-cell growth, we then studied the IGF-1/-2 ontogeny in pancreas and liver along the neonatal period.

Both groups of animals showed the same IGF-1 protein expression profile in the pancreas and liver (Fig. 4A and B). Although pancreatic IGF-1 levels were barely detectable at the beginning of the neonatal period, we did observe significantly lower values in undernourished neonates on day 4 than age-matched controls, followed by a peak in concentration at 14 days of age in both groups without differences between control and undernourished animals. Pancreatic IGF-1 levels declined in both groups at 23 days of age, but continued to be higher than at 4 days of age (Fig. 4A). As shown in Fig. 4(B), the protein levels of hepatic IGF1 increased linearly with time in both groups, but, on day 23 , the values were significantly higher (twofold) in undernourished rats as compared with controls at the same age.

Both pancreatic and hepatic IGF-2 levels decreased progressively with time in control neonates, becoming hardly detectable by postnatal day 23 (Fig. 4A and B). In undernourished animals, the timing but not the intensity of the signal for IGF-2 content was similar to control data. We found that pancreatic IGF-2 was highly expressed in undernourished rats during all the suckling period (Fig. 4A), whereas liver IGF-2 protein content was only higher in food-restricted animals at 4 and 23 days of age (Fig. 4B).

\section{Pancreatic IGFBP-1, IGFBP-2, and IGFBP-3 protein levels}

Because IGF biological actions are closely related to their binding proteins, we analyzed the local production of IGFBP-1, -2, and -3 in pancreas (Fig. 5). Both IGFBP-1 and -2 proteins showed a substantial increase with time in control neonates, whereas pancreatic IGFBP-3 protein production did not change during the neonatal period. In undernourished rats, IGFBP-1 and -2 were significantly decreased as compared with control values at 14 and 23 days of age, whereas IGFBP-3 values were lower than controls at each time point considered.

\section{Pancreatic IGF/insulin-signaling pathway}

To establish the mechanism underlying the neonatal spur of $\beta$-cell apoptosis and its partial suppression in malnourished animals, we analyzed the pancreatic IGF/insulin-signaling pathway during the neonatal life under basal conditions. IGF-1 and -2 survival and 


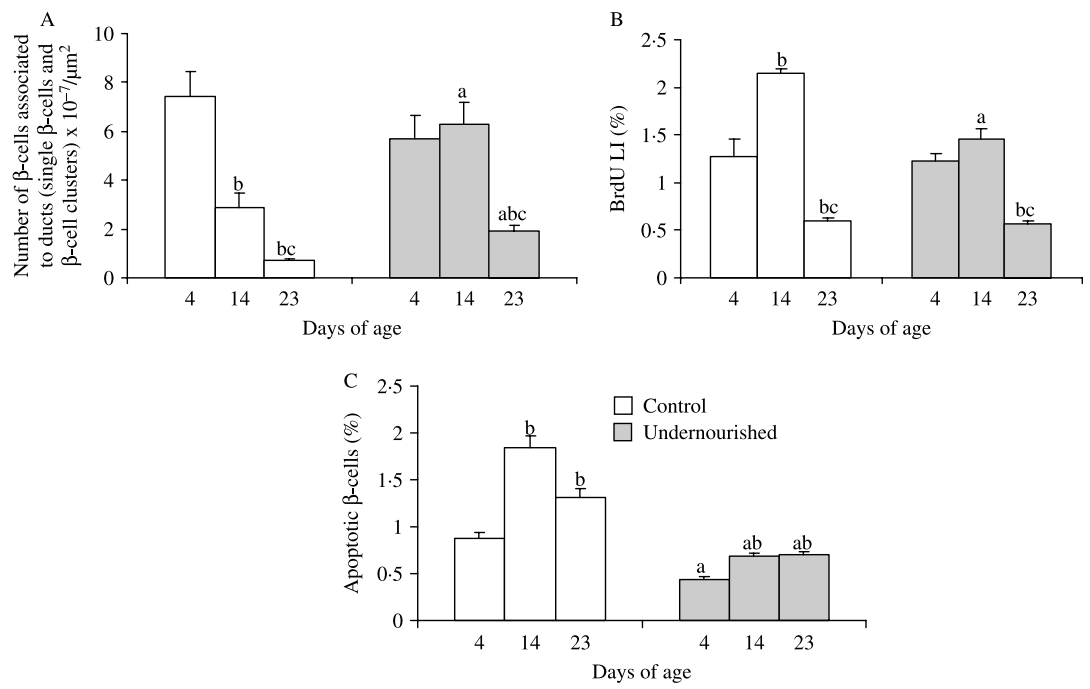

Figure 3 (A) $\beta$-Cell neoformation from ducts in control and undernourished neonatal pancreases was evaluated through quantification of single $\beta$-cells and $\beta$-cell clusters (2-4), incorporated into the ductal epithelium per unit of total tissue area. (B) Bromodeoxyuridine (BrdU) labeling index of $\beta$-cells represents $\beta$-cell replication rate in control and undernourished neonates. (C) $\beta$-Cell apoptosis rate in control and undernourished rats along the neonatal period. Apoptotic $\beta$-cells were quantified on sections double-immunostained for apoptosis and insulin. Values are mean \pm S.E.M. for four to six observations in each experimental group and age. ${ }^{a} P<0.05$ relative to control rats at the same age; ${ }^{\mathrm{b}} P<0.05$ relative to 4 days of age within the same condition; ${ }^{\mathrm{c}} P<0.05$ relative to 14 days of age within the same condition.

growth-promoting actions mainly implicate the binding to IGF-1R, although, at high IGF concentrations, the IR can also be stimulated. For this reason, we determined the total pancreatic protein content of IGF-1R/IR and its tyrosine phosphorylation in control and food-restricted rats. IGF-1R protein content increased significantly in rats fed ad libitum on postnatal day 23, whereas the pancreatic production of this receptor did not change with age in undernourished neonates. However, the ratio P-IGF1R/IGF-1R was significantly higher at 14 and 23 days of age in undernourished neonates as compared with control group (Fig. 6A). On the other hand, the IR levels increased with time in both populations without differences between control and undernourished animals. Again, when we normalized the IR rate of phosphorylation to total IR protein content, we observed a higher ratio in food-restricted neonates at 14 days of age (Fig. 6B) and no change along the suckling period in controls. The autophosphorylation of the IGF-1R/IR and activation of its tyrosine kinase activity trigger several signals including serine phosphorylation of Akt. Once activated, Akt regulates the expression and activity of many proteins involved in cell survival and apoptosis. We found no differences in total pancreatic Akt levels due to maternal malnutrition, although the activated form of Akt was markedly higher in the pancreas from undernourished neonates as compared with controls from 14 days of age onwards (Fig. 6C). Because Akt phosphorylation of Bad on Ser136 causes its inactivation, preventing its association with the anti-apoptotic protein $\mathrm{Bcl}-\mathrm{x}_{\mathrm{S} / \mathrm{L}}$ and, therefore, resulting in increased cell survival, we analyzed both proteins by western blot (Fig. 6C). Bcl- $\mathrm{x}_{\mathrm{S} / \mathrm{L}}$ protein expression gradually increased with age in both populations, although we did not find any difference between groups because of diet. On the contrary, and despite pancreatic Bad content also increased linearly with age in both groups of animals, total Bad protein was lower in food-restricted neonates than in controls at each time point considered. However, pancreatic phospho-Bad levels were similar in both groups. Another mechanism of Akt for promoting cell survival is the phosphorylation-inactivation of GSK- $3 \alpha / \beta$. We observed by western blot significantly lower activation of GSK$3 \alpha / \beta$ in the pancreas of food-restricted animals at all the neonatal ages studied. Since total pancreatic GSK- $3 \alpha / \beta$ protein content peaked on day 14 similarly in control and undernourished neonates when we expressed the data as the ratio of phosphoGSK- $3 \alpha / \beta /$ total GSK- $3 \alpha / \beta$, this ratio described a marked decrease at this age, which correlates with the increase on $\beta$-cell apoptosis observed in both groups (Fig. 6D). 

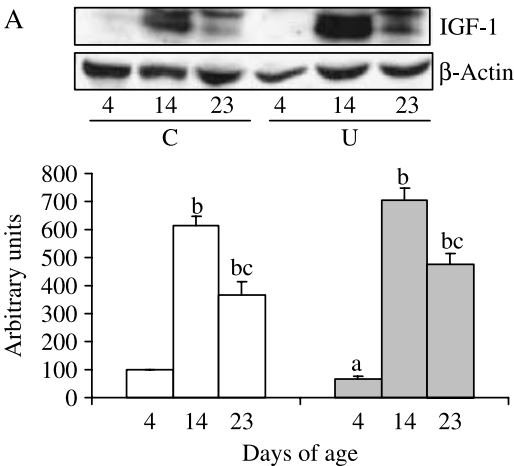

B
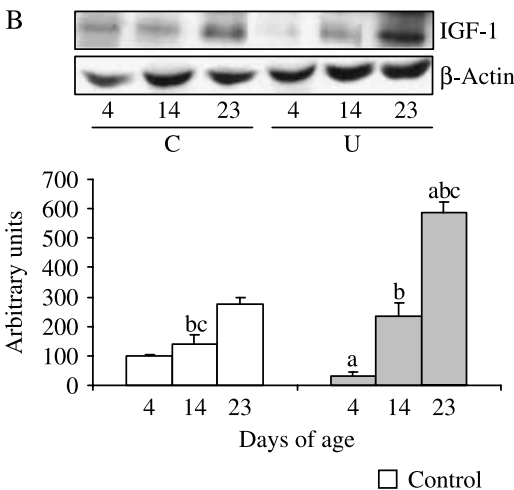
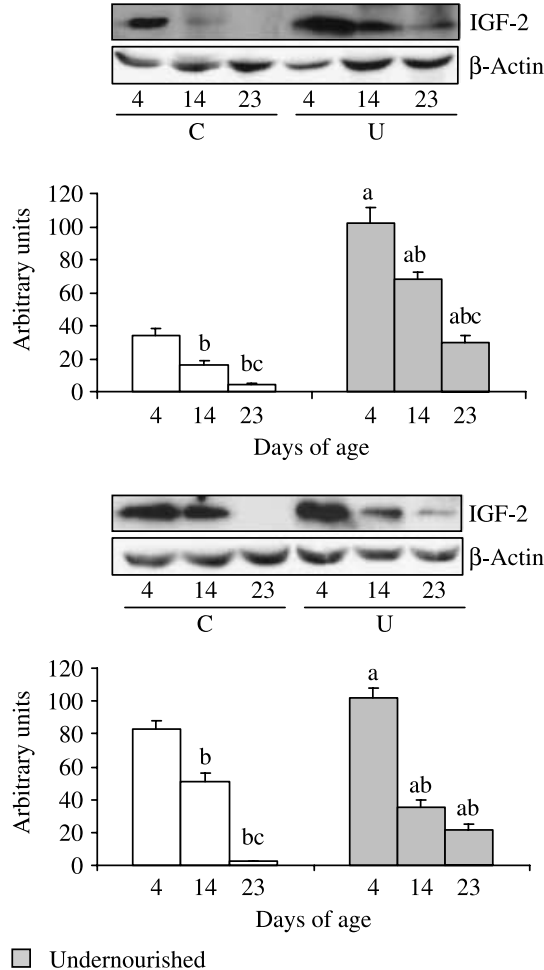

Figure 4 Pancreatic (A) and hepatic (B) IGF-2 and IGF-1 protein production in control and undernourished neonates at 4,14 , and 23 days of age. Representative western immunoblots are shown. Densitometric measurements of western immunoblots' bands are expressed as arbitrary units. Values are means \pm S.E.M. for 10-12 observations in each experimental group. Neonates were obtained from six to eight different litters. ${ }^{\text {a }} P<0.05$ relative to control rats at the same age; ${ }^{\mathrm{b}} P<0.05$ relative to 4 days of age within the same condition; ${ }^{\mathrm{C}} P<0.05$ relative to 14 days of age within the same condition.

\section{Discussion}

After birth, the $\beta$-cell population is exposed to critical challenges such as lactation with a lipid-rich milk diet followed by weaning and the change to a solid diet high in carbohydrates. These events mark a change from a fetal phenotype of $\beta$-cells to adult phenotype with altered glucose thresholds and the ability to rapidly release insulin. In this context, any alteration of dietary milieu could affect endocrine pancreas remodeling and functionality. Herein, our results indicate that the timing and intensity of neonatal $\beta$-cell ontogeny are altered by undernutrition. However, although undernutrition evokes $\beta$-cell deficiency in neonates, the endocrine pancreas preserves the capacity to regenerate as a result of an active process of $\beta$-cell neogenesis and a lower incidence of $\beta$-cell apoptosis. Interestingly, the decrease in $\beta$-cell apoptosis coincides with pancreatic IGF-2 overproduction and increased survival of insulin/IGF signaling. Therefore, our data point to that locally produced IGFs may be instrumental for the endocrine pancreas capacity of adaptation to nutritional insult.
In this developmental stage, $\beta$-cell mass from undernourished neonates was markedly lower than control values along the study. Decreased $\beta$-cell mass correlates with hypoinsulinemia but normal glycemia during all the neonatal period. This phenomenon suggests increased insulin sensitivity, as we have previously demonstrated in our animal model at 10 days of age (Gavete et al. 2005) and 3-month-old rats (Escrivá et al. 1992). Similarly, others have reported that dietary insult such as diets with high-carbohydrate (Petrik et al. 2001) or low-protein content (Petrik et al. 1999) during lactation induces alterations in islet size, number, and composition. However, specific adaptations of the endocrine pancreas to the nutritional environment differ between animal models.

In agreement with our present results, it has been previously shown that pancreatic $\beta$-cells undergo dynamic proliferative activity during the first month of life (Kaung 1994, Scaglia et al. 1997). In addition to proliferation, $\beta$-cell neogenesis contributes to $\beta$-cell mass expansion not only during fetal development but also in postnatal life (Finegood et al. 1999, Paris et al. 2004, Bonner-Weir \& Weir 2005). On this basis, in the 

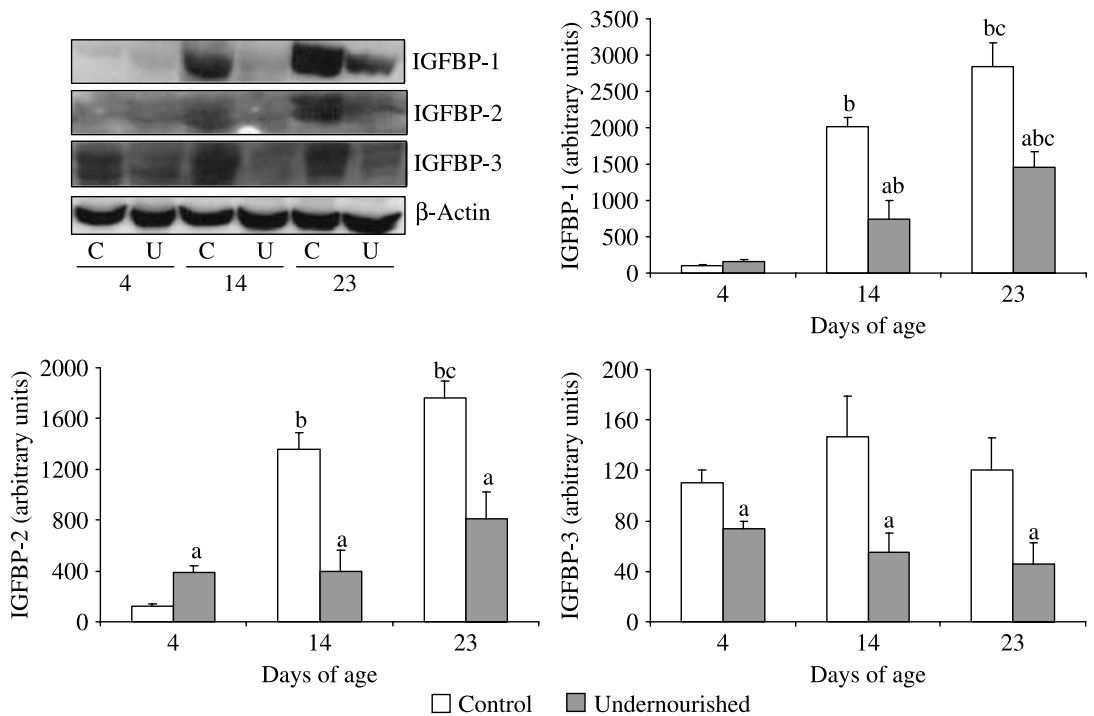

Figure 5 Pancreatic IGFBP-1, IGFBP-2, and IGFBP-3 protein levels in control and undernourished neonates at 4,14 , and 23 days of age. Blots representative of six independent determinations are shown. Results are the means \pm S.E.M. of the densitometric measurements of western immunoblots' bands expressed as arbitrary units. Neonates were obtained from six to eight different litters. ${ }^{a} P<0.05$ relative to control rats at the same age; ${ }^{b} P<0.05$ relative to 4 days of age within the same condition; ${ }^{\mathrm{c}} P<0.05$ relative to 14 days of age within the same condition.

present study, we observed that $\beta$-cell neogenesis stayed markedly active for a longer time in undernourished neonates than in control animals, whereas $\beta$-cell proliferation was damaged on day 14 . This indicates that there is a predominance of neogenesis versus replication in undernourished neonates, while, in the control group, spontaneous $\beta$-cell regeneration occurs mainly by replication. It is possible that undernutrition damages $\beta$-cells in such a manner that their ability to replicate is limited. So, although new islets can form by neogenesis in the undernourished animals it appears that they cannot get larger as reflected by the high number of very small islets in restricted pups at the end of the suckling period. This agrees with previous results obtained by our group after partial pancreatectomy of undernourished adult rats (Fernández et al. 2006) and with those observed in diabetic models induced by selective perfusion of alloxan (Waguri et al. 1997) or by the administration of low dose of streptozotocin (Bernard et al. 1999). In contrast, studies performed in rats submitted to a low-protein diet reported impaired islet cell proliferation and increased islet cell apoptosis (Petrik et al. 1999, Dumortier et al. 2007) but $\beta$-cell neogenesis when submitted to a low-energy diet (Garofano et al. 2000, Dumortier et al. 2007). Despite these discrepancies, there are several ways in which our data could be reconciled with the previously mentioned reports. First, the composition or the daily energy intake of the diet applied in other undernutrition models differs from ours. Secondly, in our model of maternal undernutrition, pregnant rats exhibit impaired insulin secretion in vivo and glucose intolerance at the end of the gestation (Alvarez et al. 1997). This disturbance of maternal glucose homeostasis, similar to that reported in mild diabetic mothers (Holemans et al. 2003), may induce a specific program in the offspring $\beta$-cell growth capacity with later detrimental consequences in $\beta$-cell proliferative potential (Fernández et al. 2006). In any case, further investigations on all these animal models are required to fully and accurately explain the contrasts.

Since $\beta$-cell mass is the result of the balance between cell growth and death, we studied the incidence of $\beta$-cell apoptosis. Our results show, in accordance with the literature (Petrik et al. 1998), that there is a transient neonatal wave of $\beta$-cell apoptosis in the endocrine pancreas of control rats. Surprisingly, the incidence of $\beta$-cell apoptosis in food-restricted animals was significantly lower than in controls at all ages examined. Other authors have also reported that intrauterine malnutrition reduces the incidence of type 1 diabetes in non-obese diabetic mice altering $\beta$-cell apoptosis levels (Oge et al. 2007). Apparently, in view of our results, even increased $\beta$-cell neogenesis and decreased $\beta$-cell apoptosis are insufficient to restore normal $\beta$-cell mass when proliferation and $\beta$-cell mass are already affected. Recently, increased islet neogenesis in diabetes-prone rats without increased islet mass has also been reported (Kauri et al. 2007). 

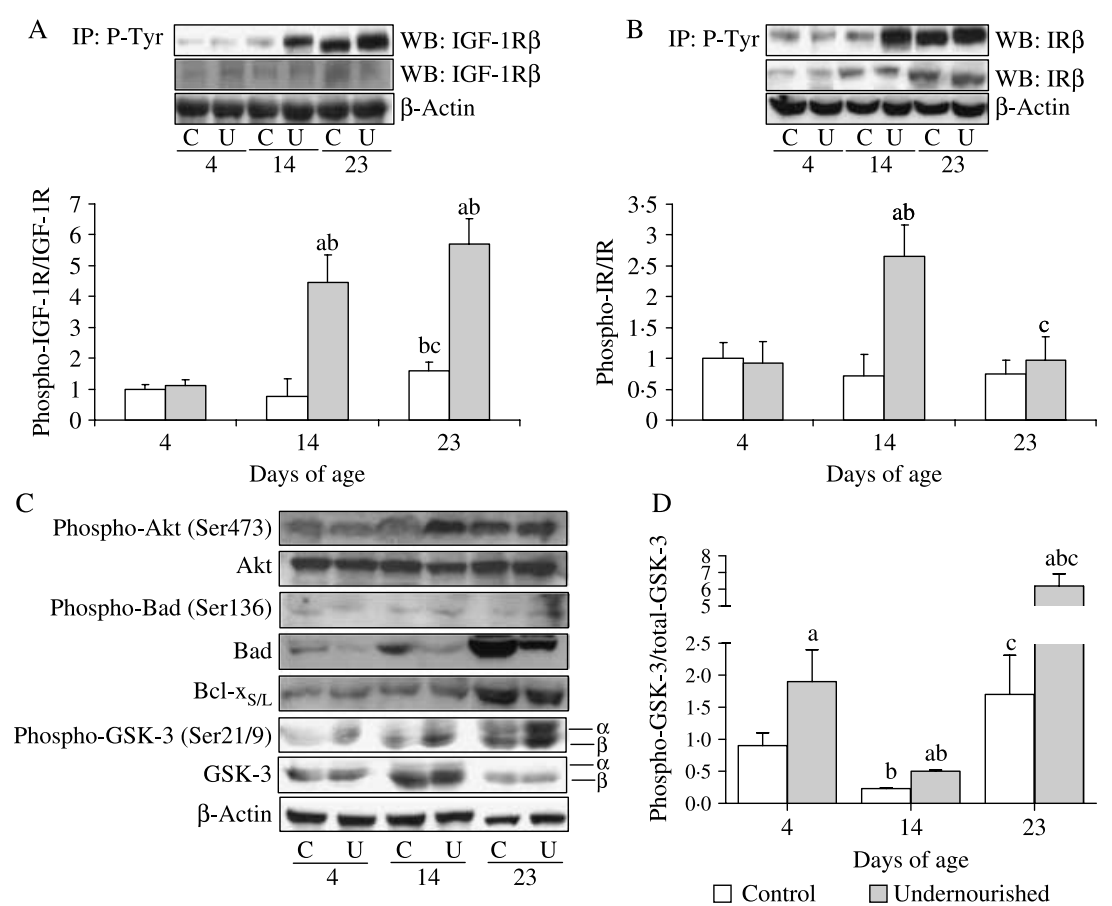

Figure 6 (A and B) Pancreatic content and phosphorylation of IGF-1/insulin receptor (IGF-1R/IR) in control and undernourished neonates at 4, 14, and 23 days of age. About $250 \mu \mathrm{g}$ of pancreas protein extracts were subjected to immunoprecipitation (IP) with the anti-phospho-tyrosine (P-Tyr) antibody. The resulting immune complexes were analyzed by western blot (WB) with the anti-IGF-1R or IR antibody. Pancreases were homogenized, and total protein was submitted to western blot and immunodetected with antibodies against total IGF-1R (A), IR (B), total Akt, GSK-3 $\alpha / \beta$, Bad and $B c l-x_{S / L}$ and the phosphorylated forms of Akt, GSK-3 $\alpha / \beta$, and Bad (C). Representative blots of at least four independent experiments are shown. The bars represent the ratio of phosphorylated to total form of IGF-1R, IR, and GSK-3 $\alpha / \beta$ (A, B, and D respectively) from densitometric measurements expressed as means \pm S.E.M. a $P<0.05$ relative to control rats at the same age; ${ }^{\mathrm{b}} P<0.05$ relative to 4 days of age within the same condition; ${ }^{\mathrm{C}} P<0.05$ relative to 14 days of age within the same condition.

The loss of regenerative capacity may be caused by the lack of one or more rate-limiting trophic stimuli. In this context, the lack of expression of IGF-2 has been associated with developmental apoptosis in the pancreatic islet cells of neonatal rat (Petrik et al. 1998), whereas IGF-2 overexpression abolishes islet cell death (Hill et al. 2000). Interestingly, we have found in the present study that undernutrition enhances pancreatic IGF-2 expression in neonates, in agreement with previous works that have reported nutritional upregulation of IGFs in pancreas under conditions of global food restriction (Martín et al. 2005, Fernández et al. 2007, Gatford et al. 2008). However, it contrasts with the effect of low-protein diet on the IGF axis, which induces a reduction in pancreatic IGF-2 expression (Petrik et al. 1999). These differences may be due to the nature and severity of the nutrient deficit.

On the other hand, it has been described that IGF-1 is expressed in areas of regeneration after partial pancreatectomy (Smith et al. 1991, Fernández et al. 2006).
Therefore, it is likely that the increase in pancreatic IGF-1 observed on day 14 responds to the need for growth factors in focal areas, which are undergoing an active process of spontaneous remodeling. To our knowledge, it is the first time that a peak of pancreatic IGF-1 content is reported at this age. Thus, it is noteworthy that this peak coincides temporally with an important rise in the mitotic index of $\beta$-cells in control neonates, whereas it does with high levels of $\beta$-cell neogenesis in undernourished rats. Likewise, the effect of IGF-2 on $\beta$-cell expansion could be due in part to its function as islet neogenic factor; however, we hypothesize that the increased pancreatic IGF-2 production in undernourished neonates is mainly related to the partial suppression of the $\beta$-cell apoptosis observed. Nonetheless, because maternal food restriction enhances pancreatic IGF-2 content and delays its physiological drop in this tissue, high levels of IGF-1 and -2 are present in pancreas at the same time, which makes difficult to distinguish the specific effects of each growth factor. In any case, it is known that insulin and IGF-1/-2 
mediate their effects via the IR and IGF-1R respectively. Considering the high degree of homology between the IR and the IGF-1R, and that IGF-2 binds with almost comparable affinity to both IR and IGF-1R (Nakae et al. 2001), it is likely that under our conditions of local high IGF-2 production, this ligand can also act via IR. Here, we show a higher phosphorylation of IGF-1R/IR in the pancreas from undernourished animals. IGF-1R/IR activation is critical for Akt-mediated survival signaling (Ueki et al. 2006). Concerning that, we have observed a higher Ser phosphorylation of Akt in food-restricted animals and, subsequently, a lower activation of GSK- $3 \alpha / \beta$ during the suckling period. Previous studies have demonstrated that inhibition of GSK-3 protected $\beta$-cells from non-esterified fatty acids (NEFA)- or endoplasmic reticulum stress-induced apoptosis (Srinivasan et al. 2005, Mussmann et al. 2007). Certainly, GSK-3 may not be the only mediator of the partial suppression of $\beta$-cell apoptosis observed in undernourished neonates, as other distal signals have also been implicated in $\beta$-cell apoptosis.

The relative contribution of locally produced IGFs to $\beta$-cell expansion could be regulated within islets by changes in the pancreatic set of IGFBPs in response to age or nutritional insult. Since the affinity of IGFBPs for IGFs is greater than the affinity of IGF-1R towards IGFs (Mohan \& Baylink 2002), the increase of pancreatic IGFBP production in control neonates at 14 and 23 days of age might prevent the interaction of IGFs with IGF-1R and, consequently, limit the survival actions of IGFs. On the contrary, the lower pancreatic levels of IGFBP-1, -2, and -3 in undernourished neonates could favor an increase in free IGF to interact with IGF-1R/IR. Furthermore, several in vivo and in vitro studies show IGF-independent actions of IGFBPs, including effects on cell apoptosis (Perks $e t$ al. 1999, Chen \& Ferry 2006, Frommer et al. 2006). However, in view of the markedly high serum IGF-1 levels found in undernourished rats, we cannot exclude a systemic effect on $\beta$-cell growth.

In summary, our present data show that food restriction induces endocrine pancreas immaturity delaying the physiological drop of pancreatic IGF-2 and the $\beta$-cell neogenesis rate. Likewise, the partial suppression of the developmental wave of $\beta$-cell apoptosis in undernourished neonates could challenge the correct turnover of $\beta$-cells from fetal to adult phenotype, resulting in a loss of islet functionality as we have observed in our animal model at adult age (Martín et al. 2004). We hypothesized that this period of natural developmental plasticity of $\beta$-cells would allow the identification of mechanisms for $\beta$-cell replacement after depletion due to nutritional insult. Therefore, understanding differences in the relationship between the IGF system and processes of $\beta$-cell regeneration may lead to therapeutic and preventive interventions in diabetic patients with previous episodes of undernutrition.

\section{Declaration of interest}

The authors declare that there is no conflict of interest that would prejudice the impartiality of this scientific work.

\section{Funding}

This work was supported by grants from Ministerio de Educación y Ciencia (BFU2005-02849 and BFU2008-02930) and by CIBER de Diabetes y Enfermedades Metabólicas Asociadas (CIBERDEM), which is an ISCIII project (Madrid, Spain). E Fernández-Millán is a recipient from CIBERDEM. Parts of this work were presented at the 44th Annual Meeting of EASD, Rome, Italy, 2008.

\section{Acknowledgements}

We thank Dr Luis Goya for critical review of this manuscript.

\section{References}

Alvarez C, Martín MA, Goya L, Bertin E, Portha B \& Pascual-Leone AM 1997 Contrasted impact of maternal rat food restriction on the fetal endocrine pancreas. Endocrinology 138 2267-2273.

Bernard C, Berthault MF, Saulnier C \& Ktorza A 1999 Neogenesis vs. apoptosis as main components of pancreatic beta cell mass changes in glucose-infused normal and mildly diabetic adult rats. FASEB Journal 13 1195-1205.

Bertin E, Gangnerau MN, Bellon G, Bailbe D, Arbelot de Vacqueur A \& Portha B 2002 Development of beta-cell mass in fetuses of rats deprived of protein and/or energy in last trimester of pregnancy. American Journal of Physiology. Regulatory, Integrative and Comparative Physiology 283 R623-R630.

Blondeau B, Garofano A, Czernichow P \& Breant B 1999 Agedependent inability of the endocrine pancreas to adapt to pregnancy: a long-term consequence of perinatal malnutrition in the rat. Endocrinology $1404208-4213$.

Bonner-Weir S 2000 Perspective: postnatal pancreatic beta cell growth. Endocrinology 141 1926-1929.

Bonner-Weir S \& Weir GC 2005 New sources of pancreatic beta-cells. Nature Biotechnology 23 857-861.

Bradford MM 1976 A rapid and sensitive method for the quantitation of microgram quantities of protein utilizing the principle of protein-dye binding. Analytical Biochemistry 72 248-254.

Casellas A, Salavert A, Agudo J, Ayuso E, Jimenez V, Moya M, Muñoz S, Franckhauser S \& Bosch F 2006 Expression of IGF-I in pancreatic islets prevents lymphocytic infiltration and protects mice from type 1 diabetes. Diabetes 55 3246-3255.

Chen X \& Ferry RJ Jr 2006 Novel actions of IGFBP-3 on intracellular signalling pathways of insulin-secreting cells. Growth Hormone and IGF Research 16 41-48.

Dumortier O, Blondeau B, Duvillié B, Reusens B, Bréant B \& Remacle C 2007 Different mechanisms operating during different critical time-windows reduce rat fetal beta cell mass due to a maternal low-protein or low-energy diet. Diabetologia 50 2495-2503.

Escrivá F, Rodríguez C, Cacho J, Alvarez C, Portha B \& PascualLeone AM 1992 Glucose utilization and insulin action in adult rats submitted to prolonged food restriction. American Journal of Physiology 263 E1-E7.

Fernández E, Martín MA, Fajardo S, Bailbé D, Gangnerau MN, Portha B, Escrivá F, Serradas P \& Alvarez C 2006 Undernutrition does not alter the activation of beta-cell neogenesis and replication in adult rats after partial pancreatectomy. American Journal of Physiology. Endocrinology and Metabolism 291 E913-E921. 
Fernández E, Martín MA, Fajardo S, Escrivá F \& Álvarez C 2007 Increased IRS-2 content and activation of IGF-I pathway contribute to enhance beta-cell mass in fetuses from undernourished pregnant rats. American Journal of Physiology. Endocrinology and Metabolism 292 E187-E195.

Finegood DT, Weir GC \& Bonner-Weir S 1999 Prior streptozotocin treatment does not inhibit pancreas regeneration after $90 \%$ pancreatectomy in rats. American Journal of Physiology 276 E822-E827.

Frommer KW, Reichenmiller K, Schutt BS, Hoeflich A, Ranke MB, Dodt G \& Elmlinger MW 2006 IGF-independent effects of IGFBP-2 on the human breast cancer cell line Hs578T. Journal of Molecular Endocrinology 37 13-23.

Garofano A, Czernichow P \& Bréant B 1999 Effect of ageing on beta cell mass and function in rats malnourished during the perinatal period. Diabetologia 42 711-718.

Garofano A, Czernichow P \& Bréant B 2000 Impaired beta-cell regeneration in perinatally malnourished rats: a study with STZ. FASEB Journal 14 2611-2617.

Gatford KL, Mohammad SN, Harland ML, De Blasio MJ, Fowden AL, Robinson JS \& Owens JA 2008 Impaired beta-cell function and inadequate compensatory increases in beta-cell mass following intrauterine growth restriction in sheep. Endocrinology 149 5118-5127.

Gavete ML, Martín MA, Alvarez C \& Escrivá F 2005 Maternal food restriction enhances insulin-induced GLUT-4 translocation and insulin signaling pathway in skeletal muscle from suckling rats. Endocrinology 146 3368-3378.

Hill DJ, Hogg J, Petrik J, Arany E \& Han VK 1999 Cellular distribution and ontogeny of insulin-like growth factors (IGFs) and IGF binding protein messenger RNAs and peptides in developing rat pancreas. Journal of Endocrinology 160 305-317.

Hill DJ, Strutt B, Arany E, Zaina S, Coukell S \& Graham CF 2000 Increased and persistent circulating insulin-like growth factor II in neonatal transgenic mice suppresses developmental apoptosis in the pancreatic islets. Endocrinology 141 1151-1157.

Hogg J, Hill DJ \& Han VK 1994 The ontogeny of insulin-like growth factor (IGF) and IGF-binding protein gene expression in the rat pancreas. Journal of Molecular Endocrinology 13 49-58.

Holemans K, Aerts L \& Van Assche FA 2003 Lifetime consequences of abnormal fetal pancreatic development. Journal of Physiology $\mathbf{5 4 7}$ $11-20$.

Kaung HL 1994 Growth dynamics of pancreatic islet cell populations during fetal and neonatal development of the rat. Developmental Dynamics 200 163-175.

Kauri LM, Wang GS, Patrick C, Bareggi M, Hill DJ \& Scott FW 2007 Increased islet neogenesis without increased islet mass precedes autoimmune attack in diabetes-prone rats. Laboratory Investigation 87 1240-1251.

Liu W, Chin-Chance C, Lee EJ \& Lowe WL 2002 Activation of phosphatidylinositol 3-kinase contributes to insulin-like growth factor I-mediated inhibition of pancreatic beta-cell death. Endocrinology 143 3802-3812.

Martín MA, Alvarez C, Goya L, Portha B \& Pascual-Leone AM 1997 Insulin secretion in adult rats that had experienced different underfeeding patterns during their development. American Journal of Physiology. Endocrinology and Metabolism 272 E634-E640.

Martín MA, Fernández E, Pascual-Leone AM, Escrivá F \& Alvarez C 2004 Protein calorie restriction has opposite effects on glucose metabolism and insulin gene expression in fetal and adult rat endocrine pancreas. American Journal of Physiology. Endocrinology and Metabolism 286 E542-E550.

Martín MA, Serradas P, Ramos S, Fernández E, Goya L, Gangnerau MN, Lacorne M, Pascual-Leone AM, Escrivá F, Portha B et al. 2005 Proteincaloric food restriction affects insulin-like growth factor system in fetal Wistar rat. Endocrinology 146 1364-1371.

Mohan S \& Baylink DJ 2002 IGF-binding proteins are multifunctional and act via IGF-dependent and -independent mechanisms.

Journal of Endocrinology 175 19-31.
Mussmann R, Geese M, Harder F, Kegel S, Andag U, Lomow A, Burk U, Onichtchouk D, Dohrmann C \& Austen M 2007 Inhibition of GSK3 promotes replication and survival of pancreatic beta cells. Journal of Biological Chemistry 282 12030-12037.

Nakae J, Kido Y \& Accili D 2001 Distinct and overlapping functions of insulin and IGF-I receptors. Endocrine Review 22 818-835.

Oge A, Isganaitis E, Jimenez-Chillaron J, Reamer C, Faucette R, Barry K, Prybyla R \& Patti ME 2007 In utero undernutrition reduces diabetes incidence in non-obese diabetic mice. Diabetologia 50 1099-1108.

Paris M, Tourrel-Cuzin C, Plachot C \& Ktorza A 2004 Review: pancreatic beta-cell neogenesis revisited. Experimental Diabesity Research 5 111-121.

Perks CM, Newcomb PV, Norman MR \& Holly JM 1999 Effect of insulin-like growth factor binding protein-1 on integrin signalling and the induction of apoptosis in human breast cancer cells. Journal of Molecular Endocrinology 22 141-159.

Petrik J, Arany E, McDonald TJ \& Hill DJ 1998 Apoptosis in the pancreatic islet cells of the neonatal rat is associated with a reduced expression of insulin-like growth factor II that may act as a survival factor. Endocrinology 139 2994-3004.

Petrik J, Reusens B, Arany E, Remacle C, Coelho C, Hoet JJ \& Hill DJ 1999 A low protein diet alters the balance of islet cell replication and apoptosis in the fetal and neonatal rat and is associated with a reduced pancreatic expression of insulin-like growth factor-II. Endocrinology 140 4861-4873.

Petrik J, Srinivasan M, Aalinkeel R, Coukell S, Arany E, Patel MS \& Hill DJ 2001 A long-term high-carbohydrate diet causes an altered ontogeny of pancreatic islets of Langerhans in the neonatal rat. Pediatric Research 49 84-92.

Rivero F, Goya L, Alaez C \& Pascual-Leone AM 1995 Effects of undernutrition and diabetes on serum and liver mRNA expression of IGFs and their binding proteins during rat development. Journal of Endocrinology 145 427-440.

Scaglia L, Cahill CJ, Finegood DT \& Bonner-Weir S 1997 Apoptosis participates in the remodeling of the endocrine pancreas in the neonatal rat. Endocrinology 138 1736-1741.

Smith FE, Rosen KM, Villa-Komaroff L, Weir GC \& Bonner-Weir S 1991 Enhanced insulin-like growth factor I gene expression in regenerating rat pancreas. PNAS $\mathbf{8 8}$ 6152-6156.

Srinivasan S, Ohsugi M, Liu Z, Fatrai S, Bernal-Mizrachi E \& Permutt MA 2005 Endoplasmic reticulum stress-induced apoptosis is partly mediated by reduced insulin signalling through phosphatidylinositol 3-kinase/Akt and increased glycogen synthase kinase-3beta in mouse insulinoma cell. Diabetes 54 968-975.

Thissen JP, Ketelslegers JM \& Underwood LE 1994 Nutritional regulation of the insulin-like growth factors. Endocrine Reviews 15 80-101.

Ueki K, Okada T, Hu J, Liew CW, Assmann A, Dahlgren GM, Peters JL, Shackman JG, Zhang M, Artner I et al. 2006 Total insulin and IGF-I resistance in pancreatic cells causes overt diabetes. Nature Genetics 38 583-588.

Waguri M, Yamamoto K, Miyagawa JI, Tochino Y, Yamamori K, Kajimoto Y, Nakajima H, Watada H, Yoshiuchi I, Itoh N et al. 1997 Demonstration of two different processes of beta-cell regeneration in a new diabetic mouse model induced by selective perfusion of alloxan. Diabetes 46 1281-1290.

Received in final form 20 July 2009

Accepted 29 July 2009

Made available online as an Accepted Preprint 31 July 2009 